\title{
A Study on Consumer Acceptance of One-person Media Content-based Advertising
}

\author{
Dong-Yoon Kim ${ }^{1}$, Hoon-Sik Yoo ${ }^{2}$ \\ ${ }^{1}$ Student, Department of New Media, Seoul Media Institute of Technology, South of Korea, \\ dongyoon0830@gmail.com \\ ${ }^{2}$ Professor, Department of New Media, Seoul Media Institute of Technology, South of Korea, \\ hsyoo@smit.ac.kr
}

Corresponding author: Hoon-Sik Yoo

\begin{abstract}
This study examines the attitude of consumers towards advertisements within one-person broadcast contents and provide implications for effective advertisement exposure. As one-person broadcast creators (influencers) exert greater influence on the consumers, one-person broadcast contents are drawing attention as a new advertising marketing medium. Drawing on previous studies on how consumer acceptance of advertisements in one-person media such as blogs, Facebook, Instagram, and YouTube has changed, this study examined the consumers' attitude towards advertisements in various one-person broadcast platforms compared to conventional broadcast channels. Previous research on this topic is limited to YouTube, and there is no comparison with conventional broadcast channels. This study found no significant difference in the consumers' attitude toward advertisements in one-person broadcasts compared to conventional ones. It discussed the results based on previous research and news articles and suggested guidelines for advertisement exposure suitable for one-person media creators who want a positive consumer attitude towards advertisements inserted in their contents.
\end{abstract}

Keywords: One-person Media, One-person Broadcast, Influencer, Advertisement Marketing, Consumer Acceptance, Content-based Advertising

\section{Introduction}

With the diversified digital environment (e.g., mobile, video) and the popularity of social media, the one-person media and one-person broadcast industries suitable for the mobile environment are rapidly growing. One-person media refers to a communication platform through which individuals produce and share their contents through a network; one-person media can be characterized by its capability of providing video content tailored to various tastes of the public in today's increasingly segmented consumer market. In this increasingly segmented consumer market, the one-person media industry is moving to a one-person broadcast platform that provides video content produced to satisfy various tastes of the public[1]. As the influence and spread of one-person broadcast grow, the multi-channel network $(\mathrm{MCN})$ market, specialized in nurturing and managing one-person broadcast creators, is also growing, and marketing activities connected with one-person broadcast contents are also prevalent. Accordingly, the one-person broadcast creator called an influencer is gaining huge popularity and high audience ratings by eliciting viewers' sympathy through interesting information and unique affinity. As the use of 
smart devices increases, viewing of conventional public broadcasts decreases while viewing of oneperson broadcasts increases; hence, the influence of one-person broadcast creators on consumers increases, and one-person broadcast content is drawing attention as a new advertisement marketing tool.

The purpose of this study is to investigate on consumers' attitude toward advertisements in the oneperson broadcast. This study examined the main factors on the advertisement attitude, including acceptance, trust, interest, and purchase motivation, and analyzed demographic group differences (e.g., differences by gender and age group).

\section{Related Research}

This study reviewed previous research on one-person media and advertisement, examined individual characteristics of the most used one-person media such as blogs, Facebook, Instagram, and YouTube, and investigated how these characteristics were utilized as advertisement marketing tools.

\subsection{Blogs and Advertising}

Blogs are text-based one-person media operated and managed by individuals. They serve as communicator for professional information delivery, and information diffusion across the society, covering various topics such as politics, economy, and culture. They collect the information they want from news, opinions, discussions, and conversations, and then post comments to reveal their thoughts to unspecified people[2]. Because blogs have the advantage of delivering information faster than conventional media and delivering without any editing or manipulation, power bloggers' posts on product reviews on performance/function and user experiences influence the consumers' favorability, trust, purchase intention, and word-of-mouth intention[2]. Blogs are utilized as a powerful advertising marketing tool since a community is created based on the trust formed between the power bloggers and consumers, and consumers voluntarily share reviews posted on blogs with others.

\subsection{Facebook and Advertising}

Facebook enables users to form diverse personal connections based on social networks. Due to the ease of establishing a target consumer group based on subscriber's profile information and managing advertisements, companies utilize Facebook as marketing advertisement to form a bond with their customers based on the consumers' trust beyond value delivery[3]. The different strategies to deliver advertising messages can be used depending on the purpose (e.g., delivery of product-related information or establishment of a relationship with consumers), which affect the consumers' attitude and purchase motivation[4]. Furthermore, it is possible to satisfy consumers by providing customized information and contents that individuals need, to intuitively know the advertisement preference through the 'Like' or 'Comment' function, and to retain continuous communications between advertisers and users, resulting in an effective advertisement[5].

\subsection{Instagram and Advertising}

Instagram is an SNS service that communicates with other users through visual content such as photos and images, providing information and forming a consensus[6]. In particular, such features as the hashtag (\#) keyword search function that enables sharing information among people with similar interests, and the curation function that allows efficient sorting of the desired information provide an efficient communication environment to consumers[7]. Unlike Facebook, it minimizes the use of texts, providing high immersion and positive promotional effects based on its visual superiority; hence, it is 
spotlighted as an effective advertisement marketing tool[8]. However, as SNS is no longer a service that connects people to people, but rather a service for advertising exposure, Instagram's advertisement fatigue has increased. In the case of Instagram's influencer advertisements, consumers showed negative advertisement attitudes due to their perception that the posted product's promotional content was a recommendation rewarded by a company[9].

\subsection{YouTube and Advertising}

The trend of the content market is shifting from text-based to video-based. An example of platform which underwent this change is YouTube, a video sharing site. Following consumers' needs to always check new news and information, video content consumption is increasing in Internet and mobile environments. There are various online video platforms such as Africa TV and Pandora TV, but YouTube is the most actively consumed video content channel[10]. YouTube allows users to watch and share video clips without a separate subscription and upload content freely by creating an account. Furthermore, it can produce and manage various types of video content without limitation in quantity. Videos with exciting content that induce sympathy in viewers have the ripple effect among consumers actively accepting the message[10]. YouTube's video content can form a sense of intimacy and consensus, such as interactive communication with consumers and a selection of everyday materials. The biggest advantage is that it is possible to provide detailed descriptions and reviews of products as images; hence, it is possible to add more detailed product information, which was insufficient in texts or photos[11]. Through the feature of interactions with consumers, various types of customer response can be obtained through the number of views, number of subscribers, number of comments, and preferences such as "like" and "dislike"[12]. Video content platforms are preferred because it captures the information of consumer's purchase intention and market reaction through the popularity of and the attention to the content itself[12], which makes it possible to conduct effective marketing at a relatively low cost, and that many indirect advertisements can be used in a short time. Accordingly, influencer marketing using YouTube is spotlighted as a means of advertisement marketing[11].

\section{Research Methods}

\subsection{Scope}

Previous studies on one-person media covered blogs, Facebook, Instagram, and YouTube; however, there have been few studies on one-person broadcasts and advertisements. The studies did not reflect various online video platforms that provide one-person broadcast content; they were limited to YouTube with the most users. Furthermore, few comparisons with TV advertisements representing conventional traditional video media were made in previous studies. To fill this research gap, this study extended the scope to nine one-person broadcast platforms including YouTube, Facebook, Africa TV, Naver TV, Podcast, Twitch TV, Kakao TV, Twitter, and Pandora TV and examined the attitude of consumers who watched advertisements in one-person broadcast contents compared to the conventional broadcasts (terrestrial, comprehensive programming, and cable) in terms of advertisement acceptance, trust, interest, and purchase motivation.

\subsection{Survey}

A survey method was employed to collect data from the public who watched one-person broadcast contents. The survey was designed to identify the characteristics of consumers' attitude toward advertisements in one-person broadcast content compared to existing broadcasts (terrestrial, 
comprehensive programming, and cable). The respondents of this study were limited to consumers who had an experience watching one-person broadcast contents. The survey was conducted for a week from August 9 to 15, 2019, through Dataspring, an online research company, to a total of 1,051 people (approximately 200 in each age group from the 20s through the 50s; 630 men and 421 women). Among them, 767 surveys (452 men and 315 women), excluding those from the respondents who had no experience viewing the one-person broadcast, were entered for data analysis; a t-test was conducted to examine significance of the differences by gender, and analysis of variance to test significance of the differences by age group. Participants' demographic breakdowns are presented in [Table 1]. Nine oneperson broadcast platforms (YouTube, Facebook, Africa TV, Naver TV, Podcast, Twitch TV, Kakao TV, Twitter, and Pandora TV) were selected as the comparison group. The survey questionnaire was designed to collect data on the degree of advertisement acceptance, advertisement trust, advertisement interest, and purchase motivation and the plan for future one-person media viewing time compared to existing broadcasts.

[Table 1] Demographic Information of the Participants

\begin{tabular}{|c|c|c|}
\hline \multicolumn{2}{|c|}{ Total } & Frequency (\%) \\
\hline \multirow{3}{*}{ Sex } & Male & 1,051 \\
\cline { 2 - 3 } & Female & $630(59.9)$ \\
\hline \multirow{4}{*}{ Age } & $20 \mathrm{~s}$ & $421(40.1)$ \\
\cline { 2 - 3 } & $30 \mathrm{~s}$ & $209(19.9)$ \\
\cline { 2 - 3 } & $40 \mathrm{~s}$ & $210(20.0)$ \\
\cline { 2 - 3 } & $50 \mathrm{~s}$ & $215(20.5)$ \\
\cline { 2 - 3 } & $60 \mathrm{~s}$ & $209(19.9)$ \\
\hline
\end{tabular}

\section{Findings}

\subsection{Acceptance of Advertisements included on One-person Broadcast Contents}

Regarding the degree of advertisement acceptance among viewers, $46.5 \%$ of the participants reported that advertisements were acceptable (5.2\% "Very Acceptable" and 41.3\% "Acceptable), while 11.2\% reported advertisements as unacceptable (1.7\% "Very Unacceptable" and 9.5\% "Unacceptable"), as shown [Table 2].

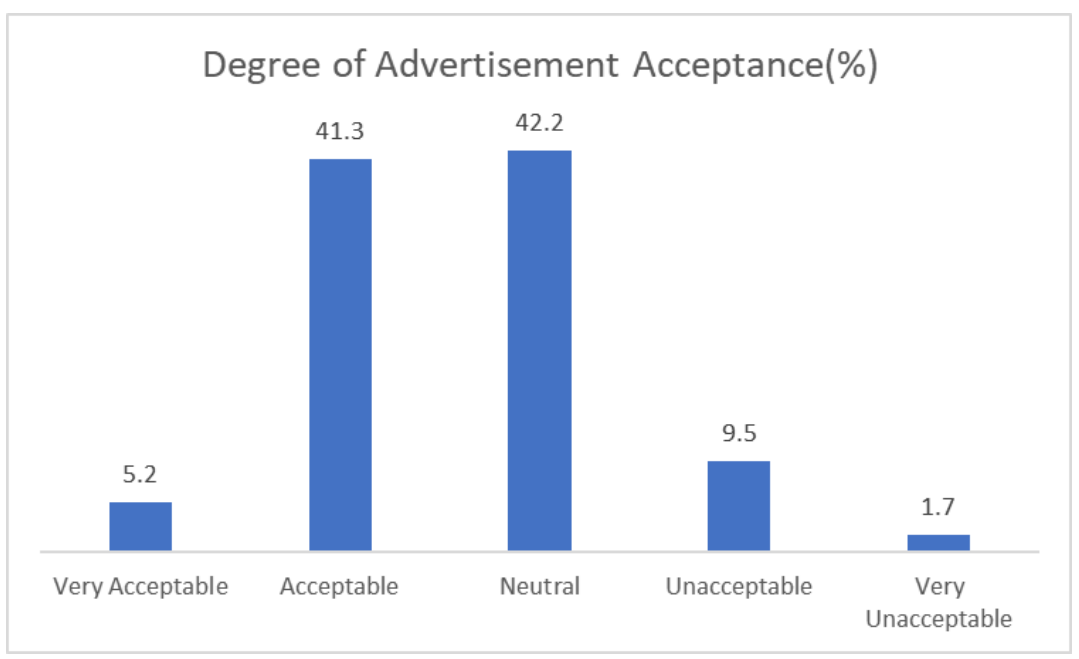

[Fig. 1] Degree of Advertisement Acceptance 
[Table 2] Degree of Advertisement Acceptance

\begin{tabular}{|c|c|c|c|c|c|c|c|}
\hline \multicolumn{2}{|c|}{} & $\begin{array}{c}\text { Frequency } \\
(\%)\end{array}$ & $\begin{array}{c}\text { Very } \\
\text { Acceptable }\end{array}$ & Acceptable & Neutral & $\begin{array}{c}\text { Unacceptabl } \\
\mathrm{e}\end{array}$ & $\begin{array}{c}\text { Very } \\
\text { Unacceptabl } \\
\mathrm{e}\end{array}$ \\
\hline \multicolumn{2}{|c|}{ Total } & 767 & $40(5.2)$ & $317(41.3)$ & $324(42.2)$ & $73(9.5)$ & $13(1.7)$ \\
\hline \multirow{2}{*}{ Gender } & Male & $452(58.9)$ & $29(6.4)$ & $189(41.8)$ & $186(41.2)$ & $40(8.8)$ & $8(1.8)$ \\
\cline { 2 - 8 } & Female & $315(41.1)$ & $11(3.5)$ & $128(40.6)$ & $138(43.8)$ & $33(10.5)$ & $5(1.6)$ \\
\hline \multirow{4}{*}{ Age } & $20 \mathrm{~s}$ & $186(24.3)$ & $17(9.1)$ & $12(6.5)$ & $5(2.7)$ & $4(2.2)$ & $2(1.1)$ \\
\cline { 2 - 8 } & $30 \mathrm{~s}$ & $168(21.9)$ & $12(7.1)$ & $67(39.9)$ & $70(41.7)$ & $15(8.9)$ & $4(2.4)$ \\
\cline { 2 - 8 } & $40 \mathrm{~s}$ & $148(19.3)$ & $5(3.4)$ & $67(45.3)$ & $61(41.2)$ & $12(8.1)$ & $3(2.0)$ \\
\cline { 2 - 8 } & $50 \mathrm{~s}$ & $133(17.3)$ & $4(3.0)$ & $51(38.3)$ & $58(43.6)$ & $18(13.5)$ & $2(1.5)$ \\
\cline { 2 - 8 } & $60+$ & $132(17.2)$ & $2(1.5)$ & $57(43.2)$ & $58(43.9)$ & $15(11.4)$ & $0(0.0)$ \\
\hline
\end{tabular}

There were no significant differences by gender and age group regarding the degree of advertisement acceptance, as presented in [Table 3] and [Table 4].

[Table 3] Degree of Advertisement Acceptance - Difference by Gender ( $\mathrm{n}=767)$

\begin{tabular}{|c|c|c|c|c|c|}
\hline \multicolumn{2}{|c|}{} & Frequency (\%) & Mean & S.D. & \multirow{2}{*}{ t-value } \\
\hline \multirow{2}{*}{ Gender } & Male & $452(58.9)$ & 2.577 & 0.811 & \multirow{2}{*}{1.418} \\
\cline { 2 - 5 } & Female & $315(41.1)$ & 2.660 & 0.775 & \\
\hline
\end{tabular}

[Table 4] Degree of Advertisement Acceptance - Difference by Age $(n=767)$

\begin{tabular}{|c|c|c|c|c|c|}
\hline \multicolumn{2}{|c|}{} & Frequency (\%) & Mean & S.D. & \multirow{2}{*}{ F-value } \\
\hline \multirow{3}{*}{ Age } & $20 \mathrm{~s}(\mathrm{a})$ & $186(24.3)$ & 2.527 & 0.839 & \\
\cline { 2 - 5 } & $30 \mathrm{~s}(\mathrm{~b})$ & $168(21.9)$ & 2.595 & 0.842 & \multirow{2}{*}{1.27} \\
\cline { 2 - 5 } & $40 \mathrm{~s}(\mathrm{c})$ & $148(19.3)$ & 2.601 & 0.771 & \\
\cline { 2 - 5 } & $50 \mathrm{~s}(\mathrm{~d})$ & $133(17.3)$ & 2.722 & 0.792 & \\
\cline { 2 - 5 } & $60+(\mathrm{e})$ & $132(17.2)$ & 2.652 & 0.699 & \\
\hline
\end{tabular}

\subsection{Trust in Advertisements included on One-person Broadcast Content compared to Existing Broadcasts (Terrestrial, Comprehensive Programming, Cable)}

On the degree of advertisement trust among viewers, $19.2 \%$ of the participants reported advertisements as trustable (2.1\% "Very Trustable" and 17.1\% "Trustable), while 26.5\% viewed advertisements as untrustable (3.9\% "Very Untrustable" and 22.6\% "Untrustable"), as shown [Table 5].

[Table 5] Degree of Advertisement Trust

\begin{tabular}{|c|c|c|c|c|c|c|c|}
\hline \multicolumn{2}{|c|}{} & $\begin{array}{c}\text { Frequency } \\
(\%)\end{array}$ & $\begin{array}{c}\text { Very } \\
\text { Trustable }\end{array}$ & Trustable & Neutral & Untrustable & $\begin{array}{c}\text { Very } \\
\text { Untrustable }\end{array}$ \\
\hline \multicolumn{2}{|c|}{ Total } & 767 & $16(2.1)$ & $131(17.1)$ & $417(54.4)$ & $173(22.6)$ & $30(3.9)$ \\
\hline \multirow{3}{*}{ Gender } & Male & $452(58.9)$ & $14(3.1)$ & $73(16.2)$ & $256(56.6)$ & $89(19.7)$ & $20(4.4)$ \\
\cline { 2 - 8 } & Female & $315(41.1)$ & $2(0.6)$ & $58(18.4)$ & $161(51.1)$ & $84(26.7)$ & $10(3.2)$ \\
\hline \multirow{4}{*}{ Age } & $20 \mathrm{~s}$ & $186(24.3)$ & $7(3.8)$ & $34(18.3)$ & $100(53.8)$ & $39(21.0)$ & $6(3.2)$ \\
\cline { 2 - 8 } & $30 \mathrm{~s}$ & $168(21.9)$ & $3(1.8)$ & $21(12.5)$ & $94(56.0)$ & $42(25.0)$ & $8(4.8)$ \\
\cline { 2 - 8 } & $40 \mathrm{~s}$ & $148(19.3)$ & $2(1.4)$ & $30(20.3)$ & $79(53.4)$ & $31(20.9)$ & $6(4.1)$ \\
\cline { 2 - 8 } & $50 \mathrm{~s}$ & $133(17.3)$ & $2(1.5)$ & $24(18.0)$ & $72(54.1)$ & $29(21.8)$ & $6(4.5)$ \\
\cline { 2 - 8 } & $60+$ & $132(17.2)$ & $2(1.5)$ & $22(16.7)$ & $72(54.5)$ & $32(24.2)$ & $4(3.0)$ \\
\hline
\end{tabular}




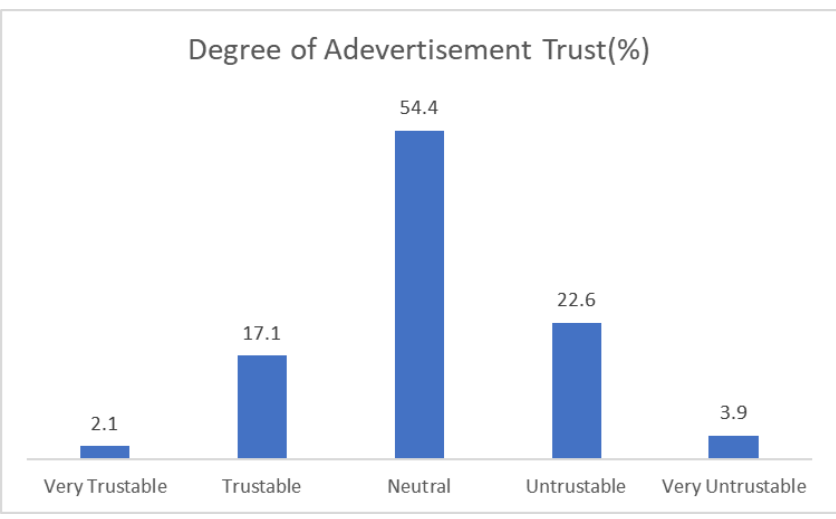

[Fig. 2] Degree of Advertisement Trust

There were no significant differences by gender and age group regarding the degree of advertisement trust, as presented in [Table 6] and [Table 7].

[Table 6] Degree of Advertisement Trust - Difference by Gender ( $\mathrm{n}=767)$

\begin{tabular}{|c|c|c|c|c|c|}
\hline \multicolumn{2}{|c|}{} & Frequency (\%) & Mean & S.D. & t-value \\
\hline \multirow{3}{*}{ Gender } & Male & $452(58.9)$ & 3.062 & 0.810 & \multirow{2}{*}{1.227} \\
\cline { 2 - 5 } & Female & $315(41.1)$ & 3.133 & 0.766 & \\
\hline
\end{tabular}

[Table 7] Degree of Advertisement Trust - Difference by Age ( $n=767)$

\begin{tabular}{|c|c|c|c|c|c|}
\hline \multicolumn{2}{|c|}{} & Frequency (\%) & Mean & S.D. & F-value \\
\hline \multirow{7}{*}{ Age } & $20 \mathrm{~s}(\mathrm{a})$ & $186(24.3)$ & 3.016 & 0.822 & \\
\cline { 2 - 5 } & $30 \mathrm{~s}(\mathrm{~b})$ & $168(21.9)$ & 3.185 & 0.779 & \multirow{2}{*}{1.07} \\
\cline { 2 - 5 } & $40 \mathrm{~s}(\mathrm{c})$ & $148(19.3)$ & 3.061 & 0.793 & \\
\cline { 2 - 5 } & $50 \mathrm{~s}(\mathrm{~d})$ & $133(17.3)$ & 3.098 & 0.796 & \\
\cline { 2 - 5 } & $60+(\mathrm{e})$ & $132(17.2)$ & 3.106 & 0.764 & \\
\hline
\end{tabular}

\subsection{Interest in Advertisements included on One-person Broadcast Contents compared to Existing Broadcasts (Terrestrial, Comprehensive Programming, Cable)}

In terms of the degree of advertisement interest among viewers, $37 \%$ of the participants reported they are interested in the advertisement (5.1\% "Very Interested" and 31.9\% "Interested), while 19.5\% reported they are uninterested (3.8\% "Very Uninterested" and $15.7 \%$ "Uninterested"), as presented in [Table 8].

[Table 8] Degree of Advertisement Interest

\begin{tabular}{|c|c|c|c|c|c|c|c|}
\hline \multicolumn{2}{|c|}{} & $\begin{array}{c}\text { Frequency } \\
(\%)\end{array}$ & $\begin{array}{c}\text { Very } \\
\text { Interested }\end{array}$ & Interested & Neutral & Uninterested & $\begin{array}{c}\text { Very } \\
\text { Uninterested }\end{array}$ \\
\hline \multirow{2}{|c|}{ Total } & 767 & $39(5.1)$ & $245(31.9)$ & $334(43.5)$ & $120(15.6)$ & $29(3.8)$ \\
\hline \multirow{3}{*}{ Gender } & Male & $452(58.9)$ & $28(6.2)$ & $141(31.2)$ & $201(44.5)$ & $69(15.3)$ & $13(2.9)$ \\
\cline { 2 - 8 } & Female & $315(41.1)$ & $11(3.5)$ & $104(33.0)$ & $133(42.2)$ & $51(16.2)$ & $16(5.1)$ \\
\hline \multirow{5}{*}{ Age } & $20 \mathrm{~s}$ & $186(24.3)$ & $14(7.5)$ & $72(38.7)$ & $66(35.5)$ & $25(13.4)$ & $9(4.8)$ \\
\cline { 2 - 8 } & $30 \mathrm{~s}$ & $168(21.9)$ & $9(5.4)$ & $54(32.1)$ & $69(41.1)$ & $31(18.5)$ & $5(3.0)$ \\
\cline { 2 - 8 } & $40 \mathrm{~s}$ & $148(19.3)$ & $4(2.7)$ & $51(34.5)$ & $63(42.6)$ & $24(16.2)$ & $6(4.1)$ \\
\cline { 2 - 8 } & $50 \mathrm{~s}$ & $133(17.3)$ & $7(5.3)$ & $35(26.3)$ & $63(47.4)$ & $22(16.5)$ & $6(4.5)$ \\
\cline { 2 - 8 } & $60+$ & $132(17.2)$ & $5(3.8)$ & $33(25.0)$ & $73(55.3)$ & $18(13.6)$ & $3(2.3)$ \\
\hline
\end{tabular}




\section{Degree of Advertisement Interest(\%)}

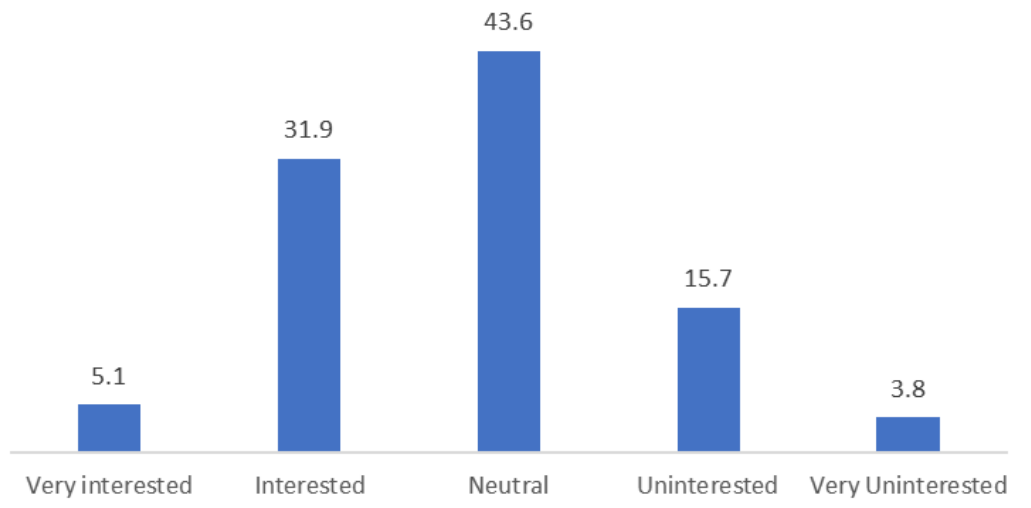

[Fig. 3] Degree of Advertisement Interest

There were no significant differences by gender and age group regarding the degree of advertisement interest, as shown in [Table 9] and [Table 10].

[Table 9] Degree of Advertisement Interest - Difference by Gender $(n=767)$

\begin{tabular}{|c|c|c|c|c|c|}
\hline \multicolumn{2}{|c|}{} & Frequency (\%) & Mean & S.D. & t-value \\
\hline \multirow{3}{*}{ Gender } & Male & $452(58.9)$ & 2.774 & 0.882 & \multirow{2}{*}{1.362} \\
\cline { 2 - 5 } & Female & $315(41.1)$ & 2.863 & 0.905 & \\
\hline
\end{tabular}

[Table 10] Degree of Advertisement Interest - Difference by Age ( $\mathrm{n}=767)$

\begin{tabular}{|c|c|c|c|c|c|}
\hline \multicolumn{2}{|c|}{} & $\begin{array}{c}\text { Frequency } \\
(\%)\end{array}$ & Mean & S.D. & \multirow{2}{*}{ F-value } \\
\hline \multirow{3}{*}{ Age } & $20 \mathrm{~s}(\mathrm{a})$ & $186(24.3)$ & 2.694 & 0.963 & \\
\cline { 2 - 5 } & $30 \mathrm{~s}(\mathrm{~b})$ & $168(21.9)$ & 2.815 & 0.900 & \multirow{3}{*}{1.19} \\
\cline { 2 - 5 } & $40 \mathrm{~s}(\mathrm{c})$ & $148(19.3)$ & 2.845 & 0.871 & 0.902 \\
\cline { 2 - 5 } & $50 \mathrm{~s}(\mathrm{~d})$ & $133(17.3)$ & 2.887 & 0.783 & \\
\cline { 2 - 5 } & $60+(\mathrm{e})$ & $132(17.2)$ & 2.856 & & \\
\hline
\end{tabular}

\subsection{Purchase Motivation influenced by Advertisements in One-person Broadcast Contents compared to Existing Broadcasts (Terrestrial, Comprehensive Programming, Cable)}

Finally, concerning the degree of purchase motivation affected by advertisements, $27.5 \%$ of the participants reported that they were motivated by the advertisements they viewed $(3.1 \%$ "Very Motivated" and $24.4 \%$ "Motivated), while $36 \%$ reported that they were not motivated (6\% "Very Unmotivated" and 30\% "Motivated"), as shown in [Table 11].

[Table 11] Degree of Purchase Motivation

\begin{tabular}{|c|c|c|c|c|c|c|c|}
\hline \multicolumn{2}{|c|}{} & $\begin{array}{c}\text { Frequency } \\
(\%)\end{array}$ & $\begin{array}{c}\text { Very } \\
\text { Motivated }\end{array}$ & Motivated & Neutral & Unmotivated & $\begin{array}{c}\text { Very } \\
\text { Unmotivated }\end{array}$ \\
\hline \multicolumn{2}{|c|}{ Total } & 767 & $24(3.1)$ & $187(24.4)$ & $280(36.5)$ & $230(30.0)$ & $46(6.0)$ \\
\hline \multirow{2}{*}{ Gender } & Male & $452(58.9)$ & $19(4.2)$ & $107(23.7)$ & $174(38.5)$ & $124(27.4)$ & $28(6.2)$ \\
\cline { 2 - 8 } & Female & $315(41.1)$ & $5(1.6)$ & $80(25.4)$ & $106(33.7)$ & $106(33.7)$ & $18(5.7)$ \\
\hline \multirow{2}{*}{ Age } & $20 \mathrm{~s}$ & $186(24.3)$ & $9(4.8)$ & $55(29.6)$ & $72(38.7)$ & $38(20.4)$ & $12(6.5)$ \\
\cline { 2 - 8 } & $30 \mathrm{~s}$ & $168(21.9)$ & $6(3.6)$ & $44(26.2)$ & $55(32.7)$ & $51(30.4)$ & $12(7.1)$ \\
\hline
\end{tabular}




\begin{tabular}{|l|l|l|l|l|l|l|l|}
\hline & $40 \mathrm{~s}$ & $148(19.3)$ & $3(2.0)$ & $37(25.0)$ & $55(37.2)$ & $44(29.7)$ & $9(6.1)$ \\
\cline { 2 - 8 } & $50 \mathrm{~s}$ & $133(17.3)$ & $3(2.3)$ & $27(20.3)$ & $51(38.3)$ & $45(33.8)$ & $7(5.3)$ \\
\cline { 2 - 8 } & $60+$ & $132(17.2)$ & $3(2.3)$ & $24(18.2)$ & $47(35.6)$ & $52(39.4)$ & $5(3.8)$ \\
\hline
\end{tabular}

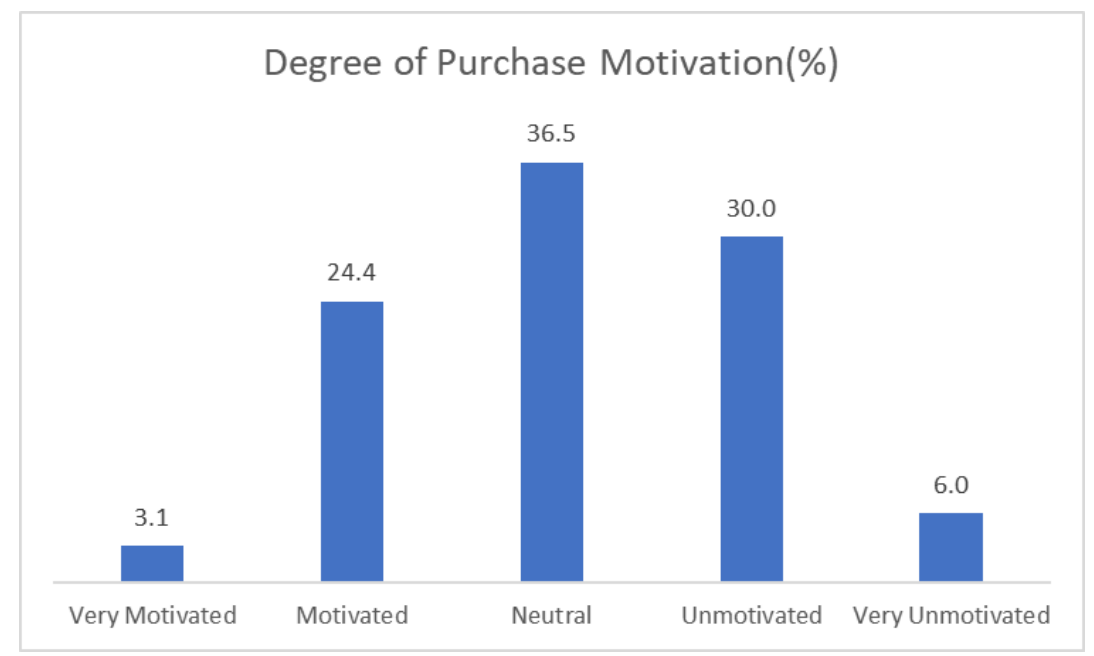

[Fig. 4] Degree of Purchase Motivation

There was no significant difference in the degree of purchase motivation between men and women [Table 12]. However, the study found a significant difference among age groups $(p<0.01)$ based on the ANOVE test, as shown in [Table 13], although the Scheffe test, a post-hoc analysis, did not show any significant pairwise difference.

[Table 12] Degree of Purchase Motivation - Difference by Gender $(n=767)$

\begin{tabular}{|c|c|c|c|c|c|}
\hline & & Frequency (\%) & Mean & S.D. & t-value \\
\hline \multirow{2}{*}{ Gender } & Male & $452(58.9)$ & 3.077 & 0.961 & \multirow{2}{*}{1.261} \\
\hline & Female & $315(41.1)$ & 3.165 & 0.926 & \\
\hline
\end{tabular}

[Table 13] Degree of Purchase Motivation - Difference by Age ( $\mathrm{n}=767)$

\begin{tabular}{|c|c|c|c|c|c|}
\hline & & Frequecy $(\%)$ & Mean & S.D. & F-value \\
\hline \multirow{5}{*}{ Age } & $20 \mathrm{~s}(\mathrm{a})$ & $186(24.3)$ & 2.941 & 0.976 & \multirow{5}{*}{$2.59^{*}$} \\
\hline & $30 \mathrm{~s}(\mathrm{~b})$ & $168(21.9)$ & 3.113 & 0.994 & \\
\hline & $40 \mathrm{~s}(\mathrm{c})$ & $148(19.3)$ & 3.128 & 0.928 & \\
\hline & $50 \mathrm{~s}(\mathrm{~d})$ & 133(17.3) & 3.195 & 0.900 & \\
\hline & $60+(e)$ & $132(17.2)$ & 3.258 & 0.888 & \\
\hline
\end{tabular}

\section{Conclusions}

This study empirically examined consumer behavior concerning advertisements included in oneperson broadcast contents, focusing on the degree of advertisement acceptance, advertisement trust, advertisement interest, and purchase motivation. First, the study conducted a t-test to examine significance of the differences by sex and analysis of variance and post-hoc analyses to examine significance of the differences by age group.

The main results of this study are as follows. First, more than half of the one-person broadcast's viewers were positive in their acceptance of advertisements in the one-person broadcast content 
compared to existing broadcasts. About $46.5 \%$ of the viewers of one-person broadcast contents turned out to be positive in accepting advertisements, while $11.2 \%$ were negative, with $42.2 \%$ being neutral. Second, the viewers of one-person broadcast contents mostly did not trust advertisements included in one-person broadcast contents compared to existing broadcasts. Approximately $26.5 \%$ of the viewers of one-person broadcast contents were negative in trusting advertisements included in the one-person media contents, with the majority (54.4\%) being neutral and $19.2 \%$ being positive. Third, in contrast to existing broadcasts, many viewers of one-person broadcasts have a high interest in advertisements in the one-person broadcast content. About $37.0 \%$ of the viewers of one-person broadcast contents were positively interested in advertisements in the one-person media content, with $43.6 \%$ being neutral and $19.5 \%$ being negative. Fourth, about $27.5 \%$ of the viewers of one-person broadcast contents reported that advertisements in one-person media content had a positive effect on their purchase motivation, with $36.5 \%$ being neutral and $36.0 \%$ being negative.

The significance and implications of this study are as follows. First, most of the previous studies were limited on the YouTube video platform that provides one-person media contents, but this study expanded the scope to various video platforms such as Africa TV and Twitch. Second, this study found that consumers were intimate with advertisements in the one-person broadcast compared to existing broadcasts. Intimacy with a one-person broadcast creator turned out to be a factor that directly affects consumers' acceptance of advertisements in the one-person broadcast content. Since advertisements are accepted as a part of the content when a trust relationship between the one-person broadcast creator and consumers is built up[11], a strategy to improve the rapport between consumers and creators should be considered when a company develops an advertisement plan in the one-person media content. Third, this study revealed that the advertisement acceptance level is higher in the one-person broadcast, but the advertisement trust level is higher in existing broadcasts. According to the 'attribution theory,' when viewers recognize that the influencer has received an economic compensation (external attribution) while they believe the influencer's product recommendation has a good motive to share a good product with them, the trust will decline. Therefore, the creator's authentic contents and ethical awareness are required to increase the trust level on advertisements in one-person broadcast content compared to existing broadcasts. Finally, advertisements included in one-person broadcast content are interesting viewers, motivating them to purchase. A study also shows that the fun and authenticity of the content not only have a significant effect on the viewers' attitude toward advertisements but also can lead to intentions to purchase[13]. Therefore, it is necessary to make the content authentic and fun to increase advertisements' conversion rate.

The limitations of this study and suggestions for future research are as follows. The subjects of this study were limited to men and women in their 20 s to 60 s. Recently, the purchasing power of teenagers like the MZ generations (millennials and $\mathrm{Z}$ generations) and adults over the age of 60 like the active senior generation is steadily increasing. Further research with subjects whose age is in the 10 s and over 60 is warranted to consider this trend.

One-person media channel is a rapidly changing field. As marketing through one-person media shows high effects, research on one-person media is expected to continue to reflect this new environment.

\section{Reference}

[1] H. J. Yu, H. Kim, The Effect of Influencer Factors in Personal Media Contents on Purchase Intention, Journal of the Korea Contents Association, (2020), Vol.20, No.1, pp.45-59, DOI : 10.5392/JKCA.2020.20.01.045

[2] H. J. Kim, H. S. Pyo, M. J. Han, Analysis on the Influences and Effects of eWOM (electronic Word of Mouth) of Power Blog Post as a Source of Advertisement, Korean Journal of Advertising and Public Relations, (2011), Vol.13, No.4, pp.315-362, UCI : G704-001035.2011.13.4.001 
[3] S. J. Lee, Examination of Factors Influencing the Attitude toward SNS-based Advertising and the Roles of Involvement: Focusing on Facebook News Feed Advertising, Journal of the Korea Contents Association, (2014), Vol.14, No.9, pp.188-202, DOI : 10.5392/JKCA.2014.14.09.188

[4] S. J. Lee, Y. S. L. Kim, A Study on the Advertising Effects According to Message Types in Corporate Facebook Page, Advertising Research, (2016), No. 108, pp.123-152, DOI : 10.16914/ar.2016.108.123

[5] H. O. Kang, The Information Sources of Facebook Multimedia Image of Social Media for Advertising Effectiveness, Journal of Digital Design, (2015), Vol.15, No.2, pp.719-728, DOI : 10.17280/jdd.2015.15.2.067

[6] J. Y. Lee, H. J. Lee, A study of Advertisement Effects in Fashion Advertising of Image-based SNS: Focused on Instagram, Proceedings of the Korea Society of Design Science Conference, Korea Society of Design Science, pp.132133, (2015), Korea

[7] S. Y. Kim, C. H. Cho, The Advertising Effect of Endorser Authenticity - Focusing on the Advertising Message from Celebrity's Instagram, Advertising Research, (2016), No.110, pp. 84-119, DOI : 10.16914/ar.2016.110.84

[8] J. K. Lee, M. G. Kim, The Effects of Consumer Value and Online Purchasing Motivations on the Advertising Effectiveness in Instagram, Korean Journal of Consumer and Advertising Psychology, (2020), Vol.21, No.1, pp.153185, DOI : 10.21074/kjlcap.2020.21.1.153

[9] M. Y. Ha, Y. J. Lee, S. J. Kwon, Y. S. Kang, J. W. Chae, Effect of Perceived Rewarded Referral on Instagram Influencer Marketing: Centering on Instagram Posts on Cosmetic Products, Journal of Digital Contents Society, (2019), Vol.20, No.1, pp.75-88, DOI : 10.9728/dcs.2019.20.1.75

[10] J. L. Park, J. E. Lim, J. S. Hwang, Communication Strategies of YouTube Brand Channel Contents, Korean Journal of Advertising and Public Relations, (2018), Vol.20, No.2, pp.95-151, DOI : 10.16914/kjapr.2018.20.2.95

[11] E. J. Kim, S. J. Hwang, A Study on Advertising Effect Depending on Type of Information Source and Displaying of Economic Support in Influencer Marketing: Focusing on YouTube, Journal of Digital Contents Society, (2019), Vol.20, No.2, pp.297-306, DOI : 10.9728/dcs.2019.20.2.297

[12] I. M. Choi, A Study on the Mere-exposure Effect of Travel Agency Advertisements on YouTube, International Journal of Tourism and Hospitality Research, (2019), Vol.33, No.5, pp.119-131, DOI : 10.21298/IJTHR.2019.5.33.5.119

[13] H. J. Yu, H. Kim, The Influence of One-Person Media Creator Content's Characteristics on Consumer Attitude and Purchase Intention: Focusing on the Creator's Credibility, Content Authenticity, and Brand Authenticity, Proceedings of the Korean Association for Broadcasting \& Telecommunication Studies Conference, Korean Association for Broadcasting \& Telecommunication Studies (2019), pp.115-117. 